\title{
Rabies Outbreak among Livestock in a Pastoralist Community, Southern Ethiopia
}

\author{
Balako Gumi $^{1 *}$, Sisay Girma ${ }^{1}$, Hussein Mohamed ${ }^{1}$, Asefa Deresa ${ }^{2}$
}

\begin{abstract}
OPEN ACCESS
Citation: Balako Gumi, Sisay Girma, Hussein Mohamed, Asefa Deresa. Rabies Outbreak among Livestock in a Pastoralist Community, Southern Ethiopia. Ethiop J Sci.2018;28(6):805.

doi:http://dx.doi.org/10.4314/ejhs.v28i6.16 Received: May 14, 2017

Accepted: September 20, 2017

Published: November 1, 2018

Copyright: (C) 2018 Balako., et al. This is an open access article distributed under the terms of the Creative Commons Attribution License, which permits unrestricted use, distribution, and reproduction in any medium, provided the original author and source are credited.

Funding: Bule Hora University

Competing Interests: The authors declare that this manuscript was approved by all authors in its form and that no competing interest exists.

Affiliation and Correspondence:

${ }^{1}$ Department of Animal Science and Range Management, Faculty of Agriculture, Bule Hora University, Ethiopia

${ }^{2}$ Ethiopian Public Health Institute, Addis Ababa, Ethiopia

*Email: balako.gumi@yahoo.com
\end{abstract}

\section{ABSTRACT}

BACKGROUND: Rabies still poses a significant health problem in most of African countries, where the majority of the cases result from dog bites. The situations in the marginalized pastoral areas were not well documented.

CASE: In September 2015, rabid wild fox entered the pastoralist village and bit a domestic dog. The victim dog had turned rabid after four months and bit livestock, and rabies outbreak occurred in the family livestock. Consequently, one bull, one lactating cow, one calf, two donkeys and one heifer died of outbreak. The head of one heifer was removed and transported within 24 hours to the Rabies Referral Laboratory of Ethiopian Public Health Institute in Addis Ababa. The sample was confirmed as strong positive for lyssa virus antigen by Direct Fluorescent Anti-Body Test. This was the first confirmed case report from southern Oromia pastoralists. The occurrence of rabies cases across the district was also reported by veterinary and human health officers.

CONCLUSION: Integrated intervention strategy and collaboration of animal health, human health and wildlife authority is needed. To halt the ongoing outbreak in the district, immediate response from the Government is recommended.

KEYWORDS: Rabies Outbreak, Pastoralists, South Ethiopia

\section{INTRODUCTION}

Rabies is caused by a negative-stranded RNA virus of the rhabdovirus family (1) and a zoonotic fatal disease that affects domestic and wild animals. It is spread to people through close contact with infectious material, usually saliva, via bites or scratches. Rabies is present on all continents with the exception of Antarctica, and more than $95 \%$ of human deaths occur in Asia and Africa. Once the symptoms of the disease have developed, rabies is nearly always fatal. People are usually infected following deep bite or scratch by an infected animal. Dogs are the main hosts and transmitters of rabies (2). According to the official WHO data, more than 2.5 billion people are at risk in over 100 countries reporting the disease. Rabies mortality ranks $10^{\text {th }}$ in all infectious diseases worldwide. There are still about 50,000 to 60,000 human deaths annually although effective vaccines for post-exposure treatment are available. The most affected are the tropical countries in Africa, Asia, South America, and Oceania (3). 
Despite the high incidence of rabies in Ethiopia, death report due to rabies was limited (4). In Ethiopia, there is lack of record keeping and appropriate reporting system on the prevalence of rabies and its impact on humans. There is also poor collaboration between the human and animal health sectors in rabies control $(4,5)$. Recently, there were increased case reports of dog bites from health facilities in Bule Hora and the pastoralist district of Goro-Dola in Guji Zones. Among those, we took outbreak case in Sirba Kebele, Goro-Dola District, in the village family livestock as case report to describe its public health implication, family psychological frustration and to inform the Government for possible intervention and control strategies.

\section{OUTBREAK SITE AND HISTORY}

Outbreak site: In 2016, rabies outbreak in the family livestock was occurred at Sirba Kebele. Sirba kebeles is located at $570 \mathrm{~km}$ from Addis Ababa in Goro-Dola pastoralists District in Guji Zone, Oromia Region, South Ethiopia (Figure 1).
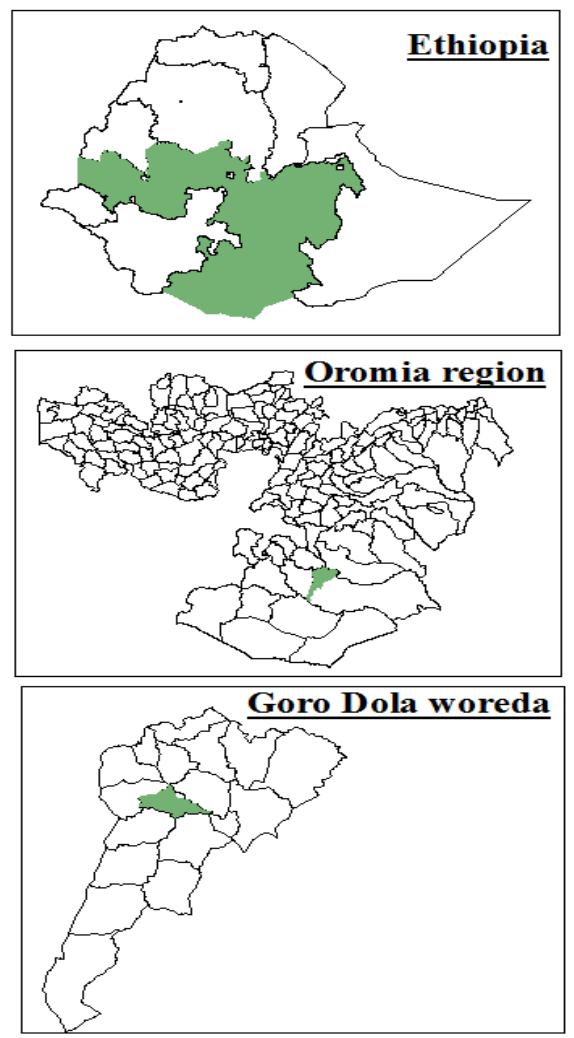

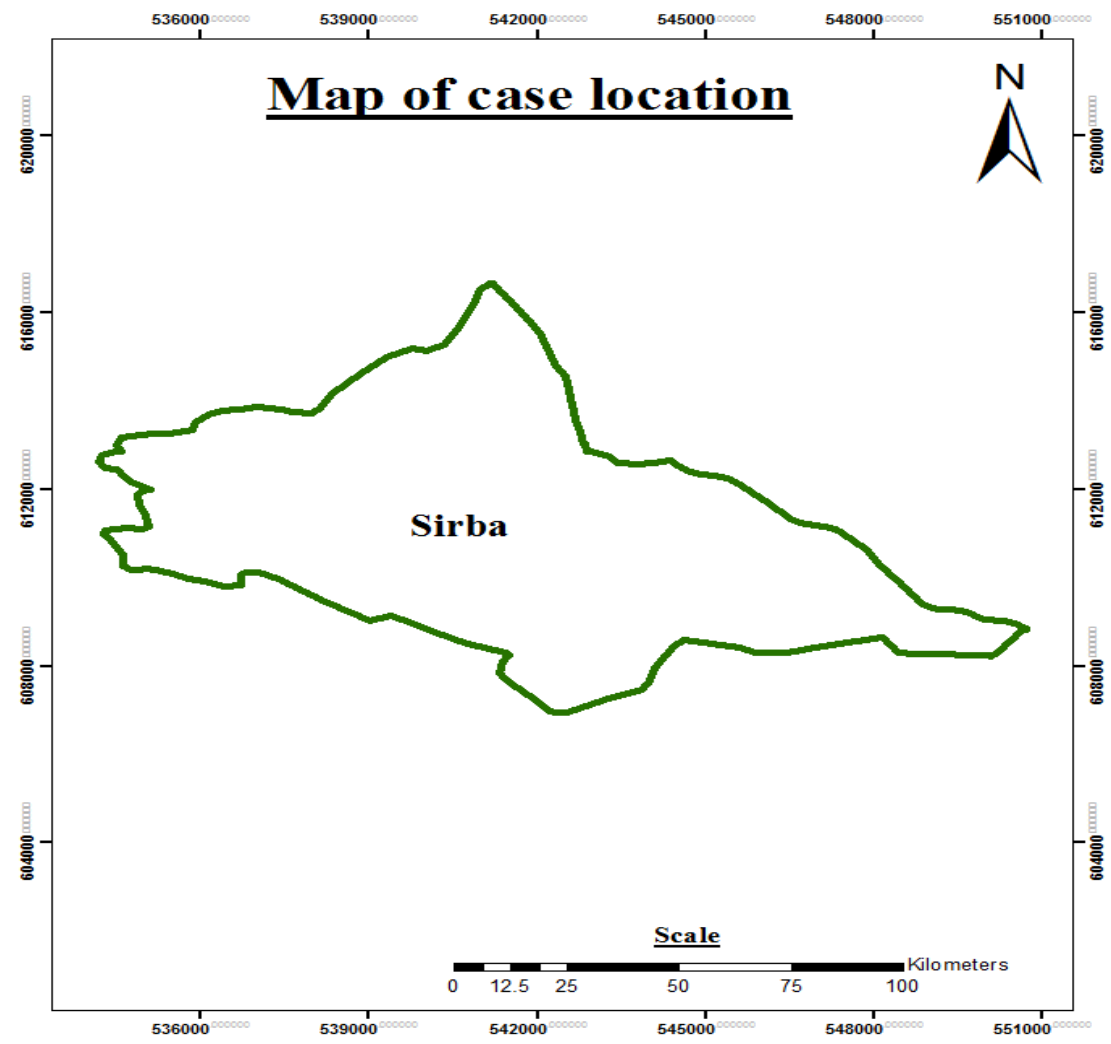

dog and exposed the family members to the traditional healer for treatment. However, three weeks later, four animals (a lactating cow, a bull, a calf and a donkey) became sick and died within a week. Even after the outbreak, the family members handling the sick animals and the exposed people in the village were not treated with post exposure vaccine and intended to go for 
further treatment by traditional healers. After a long discussion and debate, the family members and the neighbors handling the sick animals were convinced and treated with post exposure vaccine at a health center. After five months, one heifer and a donkey from a neighbor became rabid and died after a week of clinical signs. The major clinical signs observed in those rabid livestock were; in cattle: excessive salivation, behavioral change, yawning, abnormal bellowing, pica in one case (biting wooden material), a lactating cow refused calf to suckle. In donkey: aggressiveness, kicking, attempt to bite other animals, biting its own body (one case) to the level of inflicting itself. The head of one heifer was removed and transported to the Rabies Referral Laboratory of Ethiopian Public Health Institute in Addis Ababa

\section{DISCUSSION}

Rabies still poses a significant health problem in most of African, countries where the majority of the cases result from dog bites (6). In Ethiopia, rabies outbreak occurred in 2008 and 2009 in rare Ethiopian wolves (Canissimensis) (7). However, outbreak was not common in a household livestock. According to the national base line survey carried out in Ethiopia during 2013 (8), a total of 354 human rabies exposures and 45 fatal human rabies cases were reported by the selected households. The majority of human rabies victims $(86.7 \%)$ and rabies exposure cases $(79.9 \%)$ were from rural areas. Similar findings regarding the burden of rabies in rural areas were also reported from Bangladesh (9). Rabies exposure cases were reported from all regions of Ethiopia, while fatal human rabies cases were recorded only in 8 regions and in one city administration. Nevertheless, the highest exposure and fatal cases were observed in Amhara and Oromia regional states, none of the human rabies deaths was laboratory confirmed, and only few exposure cases (2.6\%) were classified as confirmed exposure cases. This may be due to lack of rabies diagnostic laboratories in all regions except Addis Ababa. Other studies also indicate that data on community's health seeking practice for rabies in Ethiopia was limited, and a significant number of cases were managed inappropriately for the sick within 24 hours. As per the post mortem protocol of rabies diagnosis, the skull of the brain was registered and dissected for choice of specimen where the brain stem, hippocampus and cerebellum were recommended. Accordingly, the Direct Fluorescent Anti-Body Test (DFAT) was performed as per the Standard Operating Procedures (SOP) set for rabies diagnosis. In this case, the calf's brain sample from the pastoralists' village in the Southern Oromia Region was confirmed as strong positive for lyssa virus antigen. This was the first confirmed case report from Southern Oromia pastoralists. In addition to outbreak in a family livestock, occurrence of rabies cases across the district were reported by the district veterinary and human health officers.

domestic animals from rabies (10). Another report by Jemberu et al in 2013 in Ethiopia indicated a high canine rabies burden, lack of sufficient awareness about the disease and high reliance on traditional treatment that interfere with timely post exposure management (11). Our outbreak case report also indicates a similar situation that family members who were handling sick animals showed low interest to receive post exposure vaccine and saught traditional healers for both animals and human treatment. Delay in post exposure vaccine in human cases increase the risk of onset of clinical rabies, which is always fatal. On the other hand, the global rabies conference vision of zero human deaths from dog-mediated rabies by 2030 (12) is unlikely to achievable in pastoralist community like in Goro-Dola District with the current attitude toward the use of post exposure vaccine and where there was no dog rabies control program exist. To eliminate rabies transmitted through dog bite, awareness creation to the dogs' owners on rabies mass vaccination is important.

In the present outbreak, the family was psychologically frustrated due to fear of occurrence of human rabies and economic impact as the result of livestock loss. The family lost economically important livestock that support family income; especially loss of bull lactating cow and donkey were immense. 
In addition to rabies outbreak cases, we made discussion with Goro-Dola District veterinary and human health officers. They reported occurrence of cases across the district in the different villages as follows, "Eight camel cases in one village, a donkey, goats and dogs deaths and a human case".

The strong trust to traditional healers and practices of handling rabies cases were interfering with timely post exposure vaccination. Rabies victims especially those from rural areas seek post exposure prophylaxis (PEP) treatment after exhausting the traditional medicinal intervention and usually after a loss of life from family members or livestock.

Successful rabies control benefits in terms of improved human and animal health and wellbeing and safer environments. A key requirement of successful and sustainable rabies control is empowering policy makers to make decisions in an efficient manner. Essential to this is the availability of evidence supporting the design and implementation of the most cost-effective strategies. It is also important to assess intervention strategies in a holistic way (13). We also recommend integrated intervention program involving animal health, human health, wildlife authority, and community awareness campaign on importance of post exposure vaccine as treatment to reduce risk of clinical rabies in human. We recommend immediate response from the Government to halt current ongoing outbreaks in the Goro-Dola pastoralist District in Guji Zone.

\section{ACKNOWLEDGMENT}

We would like to thanks Bule Hora University for the financial support to transport samples from outbreak site to the laboratory. Ethiopian Public Health Institute is also acknowledge for the diagnosis of the sample.

\section{REFERENCES}

1. Dietzschold B, Schnell M, Koprowski H. Pathogenesis of rabies. Curr Top Microbiol Immunol, 2005;292:45-56.
2. VODOPIJA R, RACZ A, PAHOR Đ. The incidence of Jackal bites and injuries in the Zagreb anti rabies clinic during 1995-2014 period. Acta Clin Croat, 2016;55:151-155.

3. HAUPT W. Rabies--risk of exposure and current trends in prevention of human cases. Vaccine. 1999; 17:1742-1749.

4. Tefera G, Yimer E, GeYid A. Endemic existence of rabies in Ethiopia. Ethiop Med J 2002;40:163.

5. Tschopp R, Bekele S, AsefFa A. Dog Demography, Animal Bite Management and Rabies Knowledge-Attitude and Practices in the Awash Basin, Eastern Ethiopia. PLoS Negl Trop Dis, 2016;10:e0004471.

6. Jibat T, Hogeveen H, Mourits MCM. Review on dog rabies vaccination coverage in Africa: a question of dog accessibility or cost recovery? PLoS Negl Trop Dis, 2015;9:e0003447.

7. Johnson N, MANSFiELd KL, MARSTON DA et al. A new outbreak of rabies in rare Ethiopian wolves (Canis simensis). Arch Virol, 2010;155:11751177.

8. Ali A, Ahmed EY, Sifer D. A Study on Knowledge, Attitude and Practice of rabies among residents in Addis Ababa, Ethiopia. Ethiop Vet J 2013;17:19-35.

9. Haque MS, Yeasmin T, Islam MM. Epidemiological Characteristics of Human Rabies at Infectious Disease Hospital, Dhaka. Bangladesh $J$ Child Health, 2012;35:102-107.

10. G/hiwot TT, Sime AG, Deresa B, Tafese W, HajtTo KW, Gemeda DH. Community Health Seeking Behavior for Suspected Human and Animal Rabies Cases, Gomma District, Southwest Ethiopia. PloS One, 2016;11:e0149363.

11. Jemberu WT, Molla W, Almaw G, Alemu S. Incidence of rabies in humans and domestic animals and people's awareness in North Gondar Zone, Ethiopia. PLoS Negl Trop Dis, 2013; 7:e2216.

12. Abela-Ridder B, KNopf L, Martin S, TAylor L, TORRES G, BALOGH KD. 2016: the beginning of the end of rabies? Lancet Glob Health, 2016;4:e780-e781.

13. Häsler B, Hiby E, Gilbert W, ObeyeseKere N, BENNANI H, RUShton J. A One Health Framework for the Evaluation of Rabies Control Programmes: A Case Study from Colombo City, Sri Lanka. PLoS Negl Trop Dis, 2014;8. doi:10.1371/journal.pntd.0003270 